\title{
ARTIGOS
}

\section{LEIBNIZ ACERCA DE ALMAS, CORPOS, AGREGADOS E SUBSTÂNCIAS NA DISCUSSÃO COM FARDELLA (1690) ${ }^{1}$}

\author{
Edgar Marques ${ }^{2}$ \\ edgarm@terra.com.br
}

RESUMO Defendo neste artigo, contra a interpretação de Robert Adams, a tese de que, na discussão com Fardella (1690), Leibniz adota uma ontologia realista, segundo a qual seres vivos, e não almas, são substâncias.

Palavras-Chave Leibniz, Mônadas, Substâncias, Formas substanciais, Corpos

ABSTRACT In this article, I sustain, against Robert Adam's interpretation, the thesis that Leibniz, in the discussion with Fardella (1690), adopts a realistic ontology, according to which live beings, instead of souls, are substances.

Keywords Leibniz, Monads, Substances, Substancial forms, Bodies

Robert Adams, em seu influente livro Leibniz. Theist, Determinist, Idealist ${ }^{3}$ defende, principalmente contra Daniel Garber, ${ }^{4}$ a tese de que

1 O presente artigo foi elaborado nos quadros de um projeto de pesquisa financiado pelo CNPq com uma bolsa de produtividade em pesquisa acerca da metafísica de Leibniz. Agradeço a Karla Chediak, que pacientemente discutiu comigo vários dos argumentos apresentados ao longo deste texto.

2 Professor do Departamento de Filosofia da UERJ. Artigo recebido em 20/05/2009 e aprovado em 29/09/2009.

3 ADAMS, 1994.

4 GARBER, D. Leibniz and the Foundation of Physics: The Middle Years. In: OKRUHLIK; BROWN (Ed.)., 1985, p. 27-130. Em textos posteriores - ver Referências -, Garber enfraqueceu um pouco suas afirmações

KRITERION, Belo Horizonte, nº 121, Jun./2010, p. 7-20. 
a metafísica leibniziana desenvolvida no período intermediário - que compreende as décadas de 1680 e 1690 - não difere essencialmente da concepção idealista presente em textos como a Correspondência com Des Bosses e a Monadologia. Seriam, de acordo com ele, idealistas - por oposição a realistas - as concepções segundo as quais a realidade é constituída, em última instância, por substâncias imateriais simples, dotadas de percepções e apetites, consistindo os corpos em fenômenos fundados nessas substâncias e em suas modificações. A posição assumida por Leibniz nesse período seria idealista nesse sentido preciso.

O idealismo, professado, segundo Adams, por Leibniz a partir da década de 1680, caracterizar-se-ia, assim, pela adesão à compreensão de que o real é constituído por dois planos ontológicos distintos, o das substâncias e o dos fenômenos, pertencendo os corpos ao segundo e as substâncias simples incorpóreas - ou, almas $^{5}$ - ao primeiro. A realidade do plano fenomênico seria derivada, portanto, da realidade do plano substancial, podendo-se dizer que, em sentido estrito, apenas as substâncias simples incorpóreas e os seus modos existiriam de fato, consistindo os corpos em uma maneira de se perceber essas substâncias, em si mesmas não corpóreas, e não em um modo de ser independente, originário e irredutível a outros modos de ser.

Uma muito forte evidência textual contrária a interpretações como a de Adams pode ser encontrada nas anotações que documentam os encontros entre Leibniz e Fardella ocorridos, em Veneza, em fevereiro e março de 1690. A certa altura, Leibniz, ao responder a uma objeção de Fardella, faz o seguinte esclarecimento: "eu não digo que o corpo é composto de almas, nem que o corpo é constituído por um agregado de almas, mas sim de substâncias. A alma, além disso, falando de maneira própria e acurada, não é uma substância, mas sim uma forma substancial, ou a forma primitiva existente nas substâncias, o primeiro ato, a primeira faculdade ativa. A força do argumento consiste em que o corpo não é uma substância, mas substâncias ou um agregado de substâncias."

iniciais, atribuindo à interpretação idealista dos textos do período intermediário uma maior plausibilidade do que aquela reconhecida por ele inicialmente. As razões desse recuo não me parecem, contudo, como veremos ao longo deste artigo, suficientemente convincentes.

5

O termo "alma" é usado aqui não no sentido técnico presente na Monadologia (parágrafo 19) de substâncias simples com percepção mais distinta e dotada de memória, mas sim no sentido mais amplo de substância simples dotada de percepção.

6 "Non dico corpus componi ex animabus, neque animarum aggregato corpus constitui; sed substantiarum. Anima autem proprie et accurate loquendo non est substantia, sed est forma substantialis seu forma primitiva inexistens substantiae, primus actus, prima facultas activa. Vis autem argumenti in hoc consistit, quod corpus non est substantia sed substantiae, seu substantiarum aggregatum" (In: LEIBNIZ, 2004, p. 1670. Tradução para o inglês: LEIBNIZ, 1989, p. 105). 
Ora, se compreendermos de maneira literal a primeira metade dessa passagem, teremos de considerar que, contrariamente à interpretação idealista da metafísica leibniziana defendida por um intérprete como Adams, Leibniz nega, nesse texto, a ideia de que almas sejam elas mesmas substâncias, reservando a elas unicamente o papel de formas substanciais, isto é, de elementos formais que necessariamente constituem as substâncias, mas que não subsistem por si mesmos de maneira independente. Se essa interpretação literal for, portanto, correta, Leibniz não pode ser considerado, ao menos no texto em questão, como patrono de uma metafísica idealista, pois ele não estaria de maneira alguma comprometido com a tese de que as almas constituiriam o plano mais fundamental da realidade, sobre o qual se assentariam os demais planos e ao qual esses, em última instância, poderiam ser reduzidos. Na verdade, parece haver na passagem até uma não tão leve insinuação de hilemorfismo do tipo aristotélico-escolástico, sugerido pelo emprego da expressão "forma substancial".

A passagem citada torna-se, contudo, ainda mais enigmática quando consideramos que Leibniz afirma, tanto na porção inicial quanto na final do texto, que corpos são agregados de substâncias, e não eles mesmos substâncias. Dessa maneira, ao menos aparentemente, Leibniz rejeita a identificação das substâncias quer com as almas quer com os corpos. O problema é que não encontramos, em sua metafísica, nenhum outro tipo de ente que emirja como potencial candidato a satisfazer os requisitos daquilo que Leibniz julga imprescindível para algo poder ser caracterizado como uma substância, a saber, unidade e atividade.

Ao analisar essa passagem das discussões com Fardella, Adams, em defesa de sua interpretação idealista da metafísica leibniziana, ${ }^{7}$ desenvolve uma exegese extremamente engenhosa e astuta, segundo a qual, em linhas gerais, Leibniz emprega aqui o termo "alma" no sentido em que o termo "enteléquia" é empregado por ele na carta a De Volder de 20 de junho de $1703,{ }^{8}$ isto é, em referência à força ativa primitiva, que, somada à força passiva primitiva - ou matéria-prima -, constitui a mônada. Dessa maneira, ao dizer a Fardella que almas não são substâncias, Leibniz não estaria, de acordo com Adams, negando a substancialidade das mônadas, mas sim unicamente que a

7 ADAMS, 1994, p. 274-277.

8 "Distinguo ergo (1) Entelechiam primitivam seu Animam, (2) Materiam nempe primam seu potentiam passivam primitivam, (3) Monada his duabas completam, (4) Massam seu materiam secundam, sive Machinam organicam, ad quam innumerae concurrunt Monades subordinatae, (5) Animal seu substantiam corpoream, quam Unam facit Monas dominans in Machinam" (LEIBNIZ, G. W. Die Philosophischen Schriften. Bd. 2. Hrsg. von C. I. Gerhardt, Georg Olms. Hildesheim, 1965. p. 252). 
força ativa primitiva tomada isoladamente constitua por si só uma substância, vale dizer, uma mônada, dado que a força passiva primitiva é um requisito indispensável da constituição da mônada.

Proporei, no presente artigo, uma interpretação alternativa à que Adams apresenta para essa passagem. Considero que Leibniz nesse texto e em outros textos desse período defende uma metafísica realista, ${ }^{9}$ de acordo com a qual os corpos vivos - e não as almas nem os corpos inertes - são as substâncias das quais a realidade se constitui.

Desenvolvo uma reconstrução conceitual do texto da discussão de Leibniz com Fardella, apresentando, em seguida, a interpretação idealista de Adams e a minha interpretação realista. ${ }^{10}$

Em fevereiro de 1690, Leibniz viajou a Veneza para realizar naquela cidade pesquisas históricas acerca da origem da família de seu protetor, o Príncipe Ernst August, tendo lá permanecido por dois meses. Durante sua estadia em Veneza, ele conheceu o padre Michel Angelo Fardella, editor das obras de Santo Agostinho, a quem decidiu expor as linhas gerais de sua metafísica. Fardella tomou nota das posições de Leibniz e as resumiu em três pequenos textos que tratam de tópicos distintos da filosofia leibniziana, tendo acrescentado objeções às ideias apresentadas no primeiro e no terceiro desses textos. Leibniz, por sua vez, após receber esse material, escreveu respostas a essas objeções. ${ }^{11}$

O corpus que documenta esse primeiro contato entre os dois filósofos é composto, assim, de textos de natureza diversa, abrigando (a) resumos feitos por Fardella da metafísica de Leibniz com base em conversas que eles tiveram, (b) comentários críticos do próprio Fardella a essa metafísica e (c) esclarecimentos de Leibniz de suas ideias à guisa de defesa. Na medida em que esses resumos não são textos escritos pelo próprio Leibniz, é salutar guardarmos uma certa precaução em relação a eles, tomando o cuidado de realizar a sua leitura à luz dos esclarecimentos que Leibniz redigiu de próprio

9 Não defendo aqui nenhuma posição em relação à metafísica leibniziana posterior a 1704, mas considero que há em vários textos, no mínimo, uma tensão entre concepções idealistas e realistas.

10 Pauline Phemister, em seu polêmico livro Leibniz and the Natural World - ver Referências -, defende também, de forma veemente, uma interpretação realista desse texto. A argumentação por ela utilizada é, todavia, distinta da desenvolvida por mim. Como meu principal objetivo neste artigo é oferecer um contraponto à interpretação idealista de Leibniz, vou me abster de registrar os pontos em que concordo ou discordo da interpretação de Phemister.

11 LEIBNIZ, 2004, p. 1666-1671. Tradução para o inglês: LEIBNIZ, 1989. 
punho para esclarecer pontos em que ele julgou ter sido mal interpretado por Fardella.

Não me ocuparei, no presente artigo, dos temas abordados nos dois primeiros resumos de Fardella e nos textos que a ele se seguem, atendo-me única e exclusivamente ao terceiro resumo e aos textos a ele correlacionados.

O terceiro resumo de Fardella (Propositio 3) versa fundamentalmente sobre o estatuto dos corpos na metafísica leibniziana. A tese principal nele defendida é a de que corpos não são eles mesmos substâncias, mas sim meros agregados de substâncias, uma vez que possuem partes, sendo daí divisíveis ao infinito. Dessa maneira, em função de serem divisíveis ao infinito e formados parte extra parte, os corpos não podem constituir uma substância singular, devendo ser compreendidos, ao contrário, como contendo em si infinitos outros corpos, os quais conteriam, por sua vez, um infinito número de substâncias. ${ }^{12}$

Caracterizados como agregados, os corpos são ontologicamente dependentes dos entes cuja agregação resulta na sua produção, isto é, a existência do agregado corporal é dependente - e derivada - da existência das unidades que constituem esse agregado. Dado que a existência de um múltiplo apenas pode ser assegurada caso seja assegurada a existência das unidades das quais esse múltiplo é constituído, os corpos somente existirão efetivamente, não se reduzindo a meras aparências ou fenômenos, caso seja afirmada a existência de unidades cuja agregação de umas às outras tem por efeito a produção de corpos. Tais unidades não serão, a seu turno, divisíveis, pois é precisamente a divisibilidade dos corpos que torna necessária a postulação da existência daquelas para assegurar a realidade destes últimos. ${ }^{13}$

O importante aqui é que se possa garantir que essas unidades possuem uma natureza distinta da dos agregados que se fundam nelas. A afirmação dessa heterogeneidade ontológica é imprescindível para afastar a possibilidade de se interpretar a relação entre os agregados corporais e as unidades que os constituem como sendo uma relação do tipo todo-parte. Essas unidades não podem ser partes das totalidades que são os corpos, pois, se assim o fosse, elas compartilhariam da natureza destes, sendo, então, divisíveis, tal como estes o são, o que entraria em contradição com seu caráter de verdadeiras unidades. ${ }^{14}$

12 "Corpus non est substantia sed aggregatum substantiarum, cum semper sit ulterius divisibile, et quaelibet pars semper aliam partem habeat in infinitum. Unde repugnat corpus esse unicam substantiam cum necessario in se involvat infinitam multitudinem, seu infinita corpora quorum quodlibet rursus infinitas substantias continet" (LEIBNIZ, 2004, p. 1668).

13 "Hinc nisi dentur substantiae quaedam indivisibiles corpora non forent realia, sed apparentiae tantum seu phaenomena sicut Iris, sublato quippe omni compositionis fundamento" (Id., Ibid., p. 1668).

14 Segue implícita nessa argumentação, obviamente, a tese de que apenas coisas de mesma natureza podem ser partes uma da outra. 
Essas unidades não são, assim, partes dos corpos, mas sim requisitos sem os quais esses não poderiam existir. Neste ponto, Fardella apela para a metáfora da linha e do ponto, dizendo que essas unidades estão para os pontos assim como os corpos estão para as linhas, indicando com isso o fato de as linhas pressuporem pontos apesar de estes não serem partes que as constituem, mas sim extremidades dos segmentos de linha que fazem, estes sim, parte das linhas. A ideia motriz da comparação é transparente: assim como as linhas - que são unidimensionais - podem ser pensadas como produtos da agregação de pontos - que são adimensionais - ainda que estes não sejam partes componentes daquelas, os corpos podem ser agregados de unidades, as quais, por possuírem uma outra natureza, não são, contudo, partes deles. ${ }^{15}$

Em resumo: por serem desprovidos de uma unidade intrínseca, os corpos devem ser compreendidos como multiplicidades resultantes da agregação de entes que constituam em si mesmos tais unidades, pressupondo, assim, a atribuição aos corpos de realidade o reconhecimento da existência de entes de um tipo distinto dos corpos, vale dizer, que não são constituídos por partes nem divisíveis ao infinito.

Encaminhada dessa forma, a reflexão parece conduzir inevitavelmente à identificação desses entes dotados de unidade intrínseca com um tipo de substância imaterial e inextensa, pois, à primeira vista, a corporeidade mesma implica tanto a composição quanto a divisibilidade ao infinito. Não causa, então, nenhuma surpresa que as linhas seguintes do texto já tragam a referência a uma substância imortal e incorpórea que não se resolve em partes. ${ }^{16}$ A compreensão dos corpos como sendo entes por agregação culmina, assim, com a postulação da existência de almas, isto é, de substâncias imateriais, unas e indivisíveis, presentes tanto nos seres humanos quanto nos animais e nas plantas. ${ }^{17}$ A essas almas parece ser atribuído, dessa maneira, o estatuto de entes ontologicamente primários sobre cuja realidade repousa a realidade dos corpos, compreendidos, consequentemente, como entes ontologicamente derivados e secundários, uma vez que a existência dos múltiplos pressupõe a existência das unidades das quais esses múltiplos se

15 "Interim non ideo dicendum est substantiam indivisibilem ingredi compositionem corporis tanquam partem, sed potius tanquam requisitum internum essentiale. Sicut punctum licet non sit pars compositiva lineae sed heterogeneum quiddam, tamen necessario requiritur ut linea sit et intelligatur" (Id., Ibid., p. 1669).

16 "Itaque in homine praeter corpus datur substantia aliqua incorporea immortalis, quippe inepta in partes resolvi" (1669).

17 "Hinc videtur probabile Bruta quae sunt valde nobis Analoga, similiter et plantas quae brutis in multis respondent non tantum [corporea] ratione verum etiam anima constare secundum quam brutum aut planta unica indivisibilis substantia permanens suarum operationum subjectum ducatur" (1669). 
compõem. Tudo indica que estamos diante da ontologia leibniziana idealista tal como ela pode ser encontrada, por exemplo, nos parágrafos iniciais de sua célebre Monadologia.

Não é de outra maneira que Fardella compreende Leibniz, a se julgar pelas objeções que ele faz às ideias apresentadas na Propositio $3 .{ }^{18}$ Fardella argumenta fundamentalmente contra a ideia de que unidades imateriais - vale dizer, almas - devam ser pressupostas para que se possa atribuir realidade aos corpos, compreendidos como entes por agregação. Seu ponto é que, não sendo as almas constituintes dos corpos, essa pretensa relação de dependência ontológica carece de sentido. Se tomarmos um ente qualquer por agregação, por exemplo, uma pilha de pedras formada pelas pedras A, B e C, podemos dizer que ao menos algumas dessas pedras devem ser apreendidas antes da apreensão da totalidade, na medida em que a apreensão desse todo que é a pilha de pedras se dá necessariamente por meio da apreensão de algumas de suas partes. ${ }^{19}$ Entretanto, o mesmo não pode ser dito da relação entre corpos e almas, pois estas não constituem aqueles, isto é, não se configuram como porções ou elementos deles. A diferença de natureza entre o múltiplo corporal e as unidades anímicas pretensamente pressupostas por aquele torna, segundo a argumentação de Fardella, praticamente ininteligível o sentido dessa relação de dependência, uma vez que está longe de ser claro por que é requisito para existência de um múltiplo algo que não o constitui, não é um seu elemento nem uma parte sua. Ou, nas palavras do próprio Fardella: “de que modo isso [a alma] é requerido para que esse agregado subsista?"20

A dificuldade a que Fardella se refere nessa passagem tem sua origem no fato de a concepção leibniziana comprometer-se ao mesmo tempo com a tese de que os corpos são derivados da agregação de certas unidades e com a ideia de que tais unidades são de natureza totalmente distinta da dos corpos. Sendo essas unidades entes de uma natureza absolutamente diversa da dos corpos, fica realmente difícil compreender como os corpos podem ser produzidos a partir da agregação delas. As imagens da pilha de pedras e da linha e do

18 "Pro multitudine lapidum $A, B, C$ debet prius intelligi lapis $A$ vel $B$ vel $C$. At non idem est in anima quae cum aliis animabus non constituit corpus. Et videtur aliquid difficultatis esse in hac ratiocinatione. Dantur in universo aggregata substantiarum corpora. Ergo datur necessario aliquid quod sit unica indivisibilis substantia. Etenim tunc consequi legitime inferretur, si haec unitas intrinsece tanquam pars hujusmodi aggregatum componeret. Nam hoc unum substantiale non constituit intrinsece aggregatum, nec est portio aliqua, sed omnino essentialiter diversum intelligitur. Quomodo igitur requiritur ut subsistat hoc aggregatum?" (1670).

19 Não custa lembrar aqui que a pilha é sempre vista de uma certa perspectiva, oferecendo-se para a visão sempre algumas das pedras que compõem a pilha. É condição para que a pilha de pedras seja vista e compreendida como pilha que mais de uma pedra se apresente simultaneamente à visão.

20 "Quomodo igitur requiritur ut subsistat hoc aggregatum?" (LEIBNIZ, 2004, p. 1670). 
ponto servem, quando introduzidas para esclarecer a natureza dos corpos, respectivamente, a propósitos distintos, reforçando a primeira a ideia de que os corpos não possuem uma unidade intrínseca, sendo agregados formados por coisas outras que a pilha mesma - no caso, as pedras -, enquanto que a segunda sublinha a heterogeneidade de natureza entre os agregados e aquilo de que eles se compõem. A aplicação dessas duas imagens para o esclarecimento da natureza de uma única coisa - os corpos - é problemática em função do fato de serem as pilhas de pedras formadas de pedras e as linhas formadas não de pontos, mas sim de segmentos de linhas. A unidade contraposta ao agregado na primeira imagem - a da pilha de pedras - constitui o agregado, mas é de mesma natureza que ele, enquanto que na segunda imagem - a da linha-ponto - a unidade não é de mesma natureza, mas não o constitui. Leibniz pensa a relação entre os corpos, qua agregados, e as unidades que são seus requisitos como sendo, de constituição, tal como na primeira imagem, mas sem envolver uma homogeneidade de natureza, tal como na segunda imagem. Corpos são, assim, tais como pilhas de pedras e como linhas, desde que especifiquemos em que sentido preciso eles se assemelham a umas e a outras respectivamente. A perplexidade de Fardella resulta da dificuldade de se aceitar que um mesmo algo possa se assemelhar a umas e outras nesses sentidos precisos e especificados.

A objeção de Fardella deve ser situada, então, no interior de uma compreensão idealista da filosofia de Leibniz. Quer dizer, é porque Fardella pensa que Leibniz sustenta a tese metafísica de que a existência de corpos exige - isto é, tem como requisito - a existência de almas (ou de algo a elas muito semelhante) como substâncias, quer dizer, como entes autônomos que subsistem por si mesmos, que ele pode solicitar esclarecimentos acerca de como almas podem ser requisitos metafísicos para a existência dos corpos, ainda que não os constituam nem façam parte deles.

A resposta de Leibniz a Fardella começa, como já vimos acima, com a negação de três teses metafísicas: (1) que corpos sejam compostos de almas; (2) que corpos sejam constituídos por agregados de almas; (3) que almas sejam substâncias propriamente ditas. Tendo em vista o contexto idealista de interpretação que torna possível a formulação da objeção de Fardella, as linhas iniciais do esclarecimento dado por Leibniz parecem ser, prima facie, a expressão de seu esforço para evitar a compreensão das almas como consistindo nas unidades substanciais cuja existência é requerida para atribuir existência aos corpos, tomados como entes por agregação, para evitar, em outras palavras, uma compreensão idealista de sua metafísica. 
Robert Adams sustenta, ${ }^{21}$ contudo, que a compreensão mais adequada dessa passagem é precisamente a idealista. Uma vez que essa interpretação parece contrariar a letra do texto leibniziano, dado que Leibniz literalmente afirma que almas não são substâncias, Adams busca, em um primeiro instante, apenas garantir para a interpretação idealista uma plausibilidade inicial que não implique já a eliminação de interpretações concorrentes, para, então, em um segundo momento, apresentar argumentos adicionais que possam inclinar a balança em favor de sua - aí, então, tornada plausível - compreensão da metafísica de Leibniz.

Adams considera que Leibniz, ao negar que a alma seja uma substância, tem em mente apenas sublinhar uma certa incompletude da alma, isto é, tem em mente dizer que a alma é só um aspecto da substância concreta, e não ela mesma uma substância concreta. Mas essa afirmação apenas pode ser plenamente compreendida caso se determine qual seria, então, a substância concreta da qual ela seria um aspecto. Basicamente duas respostas podem ser dadas aqui: ou se trata de (1) corpos orgânicos vivos - por oposição aos corpos inertes ou de (2) mônadas inextensas. No primeiro caso, atribuiríamos a Leibniz uma espécie de hilemorfismo aristotélico-escolástico, considerando as almas como formas substanciais dos corpos orgânicos vivos, enquanto que no segundo caso haveria duas possibilidades distintas de interpretação: poderíamos considerar Leibniz ou (a) um idealista full-blooded, que sustentaria haver no plano ontológico mais fundamental unicamente substâncias simples inextensas, ou, então, (b) um dualista ontológico, que reconheceria a existência de dois tipos distintos de substâncias, as simples (inextensas e de natureza espiritual) e as compostas (corpos vivos). Como o fundamental para Adams, nesse momento, é tão somente preservar a plausibilidade de uma interpretação idealista das linhas iniciais da resposta de Leibniz às objeções levantadas por Fardella à Propositio 3 , podemos deixar de lado, por enquanto, a oposição entre esse idealismo fullblooded e esse dualismo ontológico, uma vez que ambos são compatíveis com o reconhecimento de que Leibniz esteja, nas linhas em questão, simplesmente dizendo que as almas são um aspecto das mônadas, e não elas mesmas substâncias completas. Além disso, tanto esse idealismo quanto esse dualismo são rejeitados caso interpretemos Leibniz como dando a primeira resposta à questão levantada. É esse ponto preciso que nos interessa aqui.

Adams avalia, dessa maneira, que a segunda resposta seria a correta, isto é, que o que Leibniz tem em mente com a sua afirmação de que almas não são 
substâncias, mas sim formas substanciais, é simplesmente que elas constituem um aspecto das mônadas. Isso equivale a interpretar essa passagem à luz de uma distinção tornada clara posteriormente por Leibniz na carta a De Volder de 20 de junho de $1703 .{ }^{22}$ Nessa carta, Leibniz, com o propósito de esclarecer sua ontologia, distingue 5 itens: (1) a enteléquia primitiva, ou alma; (2) a matéria prima, ou força passiva primitiva; (3) a mônada, constituída a partir das duas primeiras; (4) a massa, ou matéria segunda, ou máquina orgânica; (5) o animal, quer dizer, a substância corporal, tornada uma pela mônada na máquina. De acordo com a interpretação idealista de Adams, então, o que Leibniz pretende dizer nessa passagem da discussão com Fardella é unicamente que a enteléquia primitiva, ou força ativa primitiva, não constitui por si só a mônada, devendo haver para isso também o concurso da matéria prima, ou força passiva primitiva. As substâncias das quais as almas são apenas um aspecto seriam, assim, não substâncias corporais, mas sim mônadas inextensas, pois apenas a matéria segunda é extensa, e não a matéria prima. Dessa maneira, segundo a interpretação de Adams, a afirmação, de Leibniz, de que as almas não são substâncias não implicaria a adoção por parte deste de uma ontologia na qual corpos orgânicos vivos seriam de natureza substancial, significando, pelo contrário, tão somente que a constituição das mônadas tem como requisito tanto as forças ativas primitivas quanto as passivas, não havendo mônadas caso haja a concorrência de forças de apenas um tipo. A chave para a correta interpretação dessa passagem residiria, portanto, segundo a visão de Adams, na compreensão do termo "alma" como designando naquela passagem das discussões com Fardella o item (1) - enteléquia, ou força ativa primitiva - da lista fornecida por Leibniz a De Volder, e não o item (3) - mônada.

Levando em conta a flutuação terminológica característica de Leibniz, é, ao menos inicialmente, plausível a tese de que a expressão "alma' deva ser compreendida nos termos propostos por Adams, não sendo possível, portanto, uma refutação cabal de sua interpretação. O que me proponho a fazer é examinar o restante do texto para verificar se é mais razoável sustentar essa interpretação ou se há indícios suficientes nele que apontem para uma interpretação dela distinta.

A passagem seguinte do texto parece apoiar totalmente a interpretação de Adams. Nela Leibniz afirma que a força de seu argumento consiste precisamente em ser o corpo não uma substância, mas sim um agregado de substâncias, concluindo, então que ou não há substâncias ou há algo outro que 
corpos. Leibniz vai ainda mais além, sublinhando que as substâncias agregadas que constituem os corpos não os constituem do modo como partes constituem um todo precisamente porque na relação parte-todo as partes e o todo devem ser de mesmo tipo. Logo em seguida, ele afirma que os corpos orgânicos das substâncias incluídos em qualquer massa da matéria são partes daquela massa, o que, podemos concluir, os desqualifica como candidatos ao título de substância. Adams chama a atenção, nesse contexto, para a expressão "corpos orgânicos das substâncias" [corpora organica substantiarum] presente nessa passagem e que parece indicar que as substâncias são algo outro - vale dizer, almas ou mônadas - que os corpos orgânicos.

Considero, entretanto, que o restante do texto de Leibniz fornece suficiente suporte para uma interpretação oposta a essa, qual seja, a de que os seres vivos (animais, na linguagem de Leibniz) são substâncias, e não as almas. À luz dessa interpretação essas passagens a que acabamos de nos referir ganham um novo sentido, como veremos a seguir.

$\mathrm{Na}$ frase imediatamente posterior à qual acabamos de nos referir, Leibniz faz uso da sua famosa imagem dos peixes e dos laguinhos de peixe: ele afirma que em um lago há muitos peixes e que o líquido presente no corpo de cada peixe é como se fosse um pequeno lago que contém, por sua vez, pequenos peixes ou animais, e assim ao infinito. Ele conclui daí que há substâncias em toda parte da matéria, não havendo nenhuma porção dela na qual não haja um infinito número de substâncias.

O panvitalismo de Leibniz consiste precisamente na ideia de que há vida em toda parte, isto é, que toda e qualquer porção da matéria é habitada por infinitos animais, ainda que microscópicos. O que a passagem que acabamos de ver nos mostra é que o panvitalismo se traduz, em Leibniz, em um pansubstancialismo, pois da afirmação de que os líquidos internos ao peixe são como que lagos de peixe ele retira a conclusão de que há substâncias em toda parte, sendo difícil não considerar que as substâncias que ele diz haver em toda parte são precisamente os seres vivos, os animais.

Seria possível, concedo, ainda aduzir, em favor de uma interpretação idealista, que o que Leibniz tem em mente é que havendo animais em toda parte há substâncias em toda parte pelo simples fato de os animais serem dotados de almas, as quais seriam as verdadeiras substâncias. Essa interpretação é, como sempre, possível, mas não me parece a mais adequada se queremos compreender as frases finais do texto. Vamos a elas.

Temos de considerar se podemos dizer que um animal é uma parte da matéria como um peixe é parte de um lago de peixes ou um boi é parte da manada. E, efetivamente, se o animal é concebido como uma coisa tendo partes, isto é, como um corpo divisível 
e destrutível, dotado de uma alma, então tem de ser concedido que o animal é parte da matéria, uma vez que toda parte da matéria tem partes. Mas não pode ser então concedido que é uma substância ou uma coisa indestrutível. E o mesmo vale para o homem. Pois se um homem é eu, então ele não pode ser dividido, nem pode perecer, nem pode ser uma parte homogênea da matéria. Mas se pelo nome "homem" se compreende aquilo que perece, então um homem seria parte da matéria, enquanto que aquilo que é verdadeiramente indestrutível seria chamado "alma", "mente" ou "eu”, que não seria parte da matéria.

Leibniz diferencia aqui dois modos de se pensar um animal ou um ser humano: por um lado, como parte da matéria, divisível e destrutível e, por outro, como dotado de unidade indivisível e imperecível. A contraposição reside na possibilidade de se pensar ou não o animal como análogo a um sujeito, um eu, isto é, como um centro, um foco de percepções ou representações. Assim, podemos pensar o animal simplesmente a partir de sua massa corporal extensa, representando-o, então, como divisível e destrutível. Podemos pensálo, contudo, também como um foco de percepções, quer dizer, como uma perspectiva ou ponto de vista que unifica um certo conjunto de representações. Enquanto mera massa corporal, o animal se apresenta, assim, como divisível, sendo, contudo, indivisível quando pensado como um centro de percepções, isto é, como análogo a um sujeito.

Evidentemente que essa contraposição pode ser novamente assimilada à oposição entre corpo e alma, considerando que o que há de divisível e perecível no animal é o corpo e que a alma é indivisível e imperecível. Essa assimilação é, contudo, a meu ver, desaconselhável por duas razões. A primeira, é que ela parece ignorar a negação textual de Leibniz de que a alma, falando em sentido estrito, não é uma substância, mas sim uma forma substancial. A segunda, é que ela ignora os numerosos textos contemporâneos a esse nos quais Leibniz defende a tese de que os animais não podem ser nem criados nem destruídos por processos naturais, devendo nascimento e morte ser compreendidos como processos de desdobramento de si e dobramento sobre si mesmo, respectivamente. ${ }^{23}$ Em resumo, os animais são, de acordo

23 Vejamos essa passagem do Sistema novo, de 1695: "Mas restava ainda a questão mais importante acerca do que se tornam essas almas ou essas formas quando da morte do animal ou quando da destruição do indivíduo da substância organizada. [...] somente haveria uma posição racional a assumir: a da conservação não somente da alma, mas ainda do animal mesmo e de sua máquina orgânica, embora a destruição de suas partes grosseiras o tenha reduzido a uma pequenez que escapa a nossos sentidos tanto quanto a que ele possuía antes de nascer. [...] É, então, natural que o animal, tendo sido sempre vivo e organizado, assim o permaneça para sempre. E visto que, dessa maneira, não há nem primeiro nascimento nem geração inteiramente nova do animal, segue-se que não haverá extinção final nem morte integral tomada no rigor metafísico, e que, conseqüentemente, em lugar da transmigração das almas, não há senão uma transformação de um mesmo animal, conforme os órgãos são diferentemente configurados e mais ou menos desenvolvidos" (In: LEIBNIZ, 2002, p. 20-21). 
com Leibniz, iningendráveis e imperecíveis por processos naturais por serem dotados de uma unidade inalienável, o que os torna candidatos naturais ao posto de substâncias.

Minha proposta é que interpretemos essa porção final do texto de Leibniz como uma contraposição entre a compreensão do corpo como inerte e do corpo como vivo. Como mera massa, o corpo é sujeito à divisão ao infinito, não se constituindo, assim, em uma verdadeira unidade. Por outro lado, como corpo vivo, isto é, como foco, centro de percepções, ele não se deixa dividir, preservando para sempre sua unidade. Para permanecermos em um exemplo de Leibniz, o corpo de um peixe pode ser dividido - ele pode, por exemplo, perder uma barbatana ou uma escama -, mas o peixe mesmo não se deixa dividir, isto é, não surgem a partir desse processo de divisão dois centros distintos e autônomos de percepção. Uma das duas partes - o peixe sem uma barbatana - permanece sendo um ser vivo, isto é, apresenta uma unidade orgânica que interage como um todo com o meio circundante, enquanto que a outra - a barbatana sem um peixe - não apresenta mais nenhuma unidade. Do mesmo modo, o corpo de uma pessoa é passível de divisão, mas não o sujeito que ela é. Se, por exemplo, Pedro perde um pé, o corpo de Pedro perde uma parte e se divide, formando duas massas extensas, mas não há uma divisão de Pedro. Pedro permanece sendo uno a despeito da sua perda de massa corporal. Mais importante, o pé de Pedro não se constitui em um novo sujeito - isto é, em um centro de percepções -, mas sim em uma mera massa orgânica que progressivamente se decompõe e se desestrutura.

É nesse ponto que a imagem, empregada por Leibniz, dos peixinhos e do lago pode ser esclarecedora. Como vimos, Leibniz introduz as imagens (a) da pilha de pedras e (b) da linha e do ponto para sublinhar, respectivamente, as teses (1) de que os corpos não possuem unidade intrínseca, sendo meros agregados formados a partir de unidades e (2) de que os agregados e essas unidades que os constituem possuem uma natureza heterogênea. A dificuldade expressa por Fardella resultava exatamente do fato de ser difícil compreender como as unidades podem constituir os agregados se agregados e unidades são de natureza distinta. A solução para esse enigma reside precisamente em considerar que os corpos vivos podem ser tomados ora como uma massa extensa, divisível ao infinito e ora como um ser vivo (um animal, na linguagem de Leibniz), dotado então de verdadeira unidade. Na medida em que podem ser considerados, sem que se incorra em contradição, ${ }^{24}$ como agregados e atribuídas a partir de perspectivas distintas. O corpo vivo enquanto extenso é um agregado divisível ao 
como unidades, os corpos vivos satisfazem as condições expressas pelas teses (1) e (2), podendo ser, então, caracterizados como substâncias, restando às almas o papel de formas substanciais.

Concluindo, julgo que Adams tem razão ao dizer que esse texto de Leibniz deixa de ser inconsistente ao considerarmos que um determinado termo possui nele dois sentidos distintos e que recorrendo às diferenciações feitas na carta a De Volder de 1704 podemos compreender o texto melhor. Apenas creio que o termo em questão é "corpo" e não "alma", e que a equivocidade reside no fato de que Leibniz ora o emprega no sentido do item 4 da carta a De Volder - massa, ou matéria segunda, ou máquina orgânica -, e ora no sentido do item 5 - o animal, a substância corporal, tornada uma pela mônada na máquina.

\section{Referências}

ADAMS, R. Leibniz: Determinist, Theist, Idealist. Oxford: Oxford University Press, 1994.

GARBER, D. Leibniz and Fardella: Body, Substance, and Idealism. In: LODGE, P. Leibniz and his Correspondents. Cambridge: Cambridge University Press, 2004.

GARBER, D. Leibniz and the Foundation of Physics: The Middle Years. In: OKRUHLIK, K.; BROWN, J. R. (Ed.). The Natural Philosophy of Leibniz. Dordrecht: Reidel, 1985. p. 27-130.

GARBER, D. Review of Robert Merrihew Adams: Leibniz: Determinist, Theist, Idealist. Leibniz Society Review, v. 6, p. 96-97, 1996.

JOLlEY, N. (Ed.). The Cambridge Companion to Leibniz. Cambridge: Cambridge University Press, 1995.

LEIBNIZ, G. W. Akademie-Ausgabe. Reihe VI, Band 4b, 2004.

LEIBNIZ, G.W. Philosophical Papers. Translated and edited by Ariew, R. \& Garber, D. Indianapolis; Cambridge: Hackett, 1989.

LEIBNIZ, G.W. Sistema novo da natureza e da comunicação das substâncias e outros textos. Seleção, tradução e apresentação de Edgar Marques. Belo Horizonte: Ed. UFMG, 2002.

PHEMISTER, P. Corporeal Substances and the "Discourse on Metaphysics". Studia Leibnitiana, 33-1, p. 68-85, 2001.

PHEMISTER, P. Leibniz and the Elements of Compound Bodies. British Journal for the History of Philosophy, 7-1, p. 57-78, 1999.

PHEMISTER, P. Leibniz and the Natural World. Dordrecht: Springer, 2005.

infinito, mas enquanto ser vivo possui verdadeira unidade. A contradição apenas ocorreria caso não se levasse em conta o papel lógico desempenhado nessas frases pela partícula "enquanto". Na lógica contemporânea a Leibniz o conjunto de questões relativas à predicação dos entes com base em maneiras determinadas de consideração desses entes constitui a "Lógica dos Reduplicativos". 